\title{
Reflexiones sobre la educación del sumak kawsay en Ecuador ${ }^{1}$
}

\section{Reflections on the Right to Education of sumak kawsay in Ecuador}

\author{
Fernando Lara Lara ${ }^{2}$ \\ Pontificia Universidad Católica del Ecuador Sede Santo \\ Domingo (Ecuador)
}

\section{Agustín de la Herrán Gascón ${ }^{3}$ \\ Universidad Autónoma de Madrid (España)}

Recibido: 16-03-16

Aprobado: 26-04-16

\section{Resumen}

El concepto de buen vivir -sumak kawsay (quechua) pertenece a una cosmovisión incardinada en el modelo de sociedad de distintos países sudamericanos e integrado en sus normativas sociales y educativas. La complejidad y ambición de su planteamiento recomienda y evidencia la necesidad del debate acerca de qué puede suponer ese modelo de estar en la sociedad y en el mundo, siendo calificado de utopía latinoamericana. Igualmente en el campo educativo donde se aprecia la necesaria reflexión constante acerca del alcance y significado de este derecho fundamental ante los desafíos del siglo XXI como es la sustentabilidad ambiental. El presente trabajo tiene por objeto mediante la hermenéutica normativa contribuir a la comprensión del significado del derecho a la educación en Ecuador con relación a la propuesta educativa del buen vivir, y promover la creación de una cultura política educativa coherente con los mandatos del legislador ecuatoriano.

\footnotetext{
${ }^{1}$ El presente trabajo fue patrocinado por el Proyecto Prometeo de la Secretaría de Educación Superior, Ciencia, Tecnología e Innovación (SENESCYT) de la República del Ecuador.

2 (11f@pucesd.edu.ec). Doctor Internacional en Educación por la Universidad Autónoma de Madrid (España). Licenciado en Derecho y en Ciencias Políticas y de la Administración por la Universidad de Granada (España). Profesor Titular y Director Administrativo de la Pontificia Universidad Católica del Ecuador con sede en Santo Domingo (Ecuador). Ha publicado capítulos de libros, artículos y comunicaciones en temas como personalismo, educación de mayores, legislación educativa y filosofía de la educación.

${ }^{3}$ (agustin.delaherran@uam.es) Doctor en Educación. Profesor titular de Didáctica y Organización Escolar de Universidad. Departamento de Didáctica y Teoría de la Educación. Facultad de Formación de Profesorado y Educación. Universidad Autónoma de Madrid.
} 
Palabras-clave: Legislación educativa, educación humanista, filosofía de la educación; educación cultural; programas interculturales, hermenéutica.

\begin{abstract}
The concept of good living -sumak Kawsay (quechua) belongs to a worldview that is embedded within the model of society in different South American countries and integrated in their social and educative regulations. The complexity and ambition of its approach recommend the need for debate about what the implications are for society and the world, being qualified as a Latin American utopia. In the same way, in education where it is necessary to do a constant reflection about the scope and meaning of this fundamental right in order to face the challenges of the XXI century as an example, let us take environmental sustainability. The present study intends to contribute through hermeneutical rules to the comprehension of the significance of the right to education in Ecuador in relation to the educational proposal of good living, and promote the creation of a coherent education policy mandates culture according with Ecuadorian legislator.
\end{abstract}

Key-words: Educational Legislation, Humanistic Education, Educational Philosophy, Cultural Education, Intercultural Programs, Hermeneutics.

\title{
Introducción
}

La propuesta filosófica, política y pedagógica de sociedad que plantea Ecuador (Constitución de la República del Ecuador, 2008; SENPLADES, 2013) supone un reto permanente para la sociedad ecuatoriana en general y para la comunidad educativa en particular. El intento de dar respuesta a qué puede suponer una educación para el buen vivir es un tema aún no resuelto (Illicachi, 2015; Fernández, Pardo y Salamanca, 2014), y de difícil construcción (Rodríguez, 2015) por cuanto se pretende construir una cosmovisión comunitaria. Uno de los retos claves es definir qué pedagogías podrían ser acordes con lo que Vanhulst y Beling (2014) califican como "utopía latinoamericana".

En este trabajo no se pretende realizar un análisis detallado desde las distintas normativas educativas del Ecuador, pero sí justificar la importancia de su formulación continua, dar a conocer la relevancia de su significado a los investigadores de la educación con la intención de debatir sobre qué pedagogías pueden ser susceptibles de implementación, así como ofrecer un acercamiento a su concepción para su evaluación y exigibilidad.

De este modo, resulta indispensable ofrecer una respuesta aproximativa ante el interrogante que se plantea, ¿qué puede implicar la educación del buen 
vivir en Ecuador?, precisamente para evitar plantearse una pedagogía convertida en pura logomaquia, como advierte Ortega y Gasset (Bolado, 2014). Esto es, olvidarse de la esencia de la educación, cuya finalidad reside en la formación de la persona para vivir en sociedad y en el mundo. En otras palabras, Zubiri (2005) recuerda la importancia de la conexión entre la investigación filosófica y la científica, en cuanto a la primera supone más que aprender un sistema de ideas o de pensamiento, un saber contextual, es decir, "un saber realidad y un saber hacer realidad" (Fornet- Betancourt, 2002, p. 25).

Una educación para el buen vivir, se contempla como un elemento fundamental en la construcción del modelo político, social y económico que plantea la Constitución de la República del Ecuador (2008). En efecto, parece existir cierta necesidad de reflexión pedagógica ante el cuestionamiento por parte de algunos sectores de la comunidad científica sobre la acertada construcción educativa de esta realidad intercultural. Por poner algunos ejemplos, parecen imponerse ciertas realidades culturales, como es el caso de algunas universidades indígenas, que cuestionan la eficacia del diálogo intercultural en la educación superior (Vargas, 2014).

De igual forma, en su dimensión del derecho al aprendizaje a lo largo de la vida, parece enfocarse en la franja de edad relacionada con las etapas juveniles, relegando a un segundo plano a los adultos mayores, quienes parecen ser percibidos desde una óptica reducida al asistencialismo. Por otro, parece exigirse un compromiso con la creación de conciencia de pertenencia a la Pacha Mama y un debate acerca de la dificultad de implantación práctica del proyecto político jurídico planteado por la Constitución (Rodríguez, 2015; Vanhulst y Beling, 2013). Por tanto, el interés al que se intenta responder es el de coadyuvar a la coherencia de los mandatos normativos con la realidad educativa ecuatoriana favoreciendo la creación de una cultura política educativa comprometida con la propuesta educativa del buen vivir. Una vez que sea planteada una posible respuesta, podría servir como espacio de diálogo y reflexión crítica acerca de pedagogías plausibles encaminadas a la consecución utópica de una educación del sumak Kawsay (Villagómez y Cunha de Campos, 2014).

De este modo se pretende realizar un análisis descriptivo de las principales normas jurídicas educativas ecuatorianas que, sin ser exhaustivo, ponga de relieve la importancia de la reflexión en torno a la educación como derecho, centrado en el desarrollo holístico de la persona como realidad compleja, intercultural, en formación permanente, integrante de la naturaleza y con conciencia ecológica.

Siguiendo la hermenéutica normativa, cuya finalidad es reglar el obrar (Navarro, 2010), se plantean los siguientes interrogantes como directrices del estudio: ¿qué significado pueden tener aquellos conceptos en la realidad educativa ecuatoriana? ¿Qué puede suponer el derecho a la educación en 
Ecuador? ¿Qué deben tener presentes las políticas educativas, los planes curriculares y los docentes? ¿Por qué es importante el conocimiento de la norma educativa? ¿Qué desafíos se encuentra la educación en Ecuador?

\section{Aproximación a una educación para el buen vivir en Ecuador}

\section{El derecho a la educación intercultural en Ecuador: elementos fundamentales}

La apuesta por el buen vivir, reflejada en el conjunto de la legislación educativa ecuatoriana, parece reivindicar lo que García Márquez, entre otros, se atrevió a pronunciar en su conocido discurso en el Congreso de la Lengua en Zacatecas (México) en el año 1997. Aunque lo realizó con relación a la normatividad ortográfica, puede ser extrapolable a la cuestión aquí planteada, por cuanto aconsejaba como necesario "humanizar" las leyes y "aprender" de aquellos pueblos históricamente excluidos: indígenas principalmente, pero también de otros pueblos que siguen estando presentes. En Ecuador sería el caso, entre otros, de sirios, libios, palestinos y judíos que arribaron a este país durante los siglos XIX y XX (Hurtado, 2014).

Por lo tanto, el desafío del discurso intercultural moderno del buen vivir que se traslada a las normas ecuatorianas debería tener como un eje fundamental la reflexión crítica de una didáctica de lo qué pueden o no aportar los demás pueblos que se han ubicado en el Ecuador a lo largo de su historia, como refleja la Constitución. De lo contrario, el discurso intercultural perdería sentido, pues sería reduccionista y excluyente. En el preámbulo de la Constitución Ecuatoriana se reconoce expresamente la importancia de la regresión al pasado milenario para apostar por una nueva forma de convivencia en la que la persona (reconociendo todas sus dimensiones), la riqueza de las distintas culturas y la armonía con la naturaleza son elementos cardinales.

Por supuesto, este reconocimiento expreso y abierto diacrónica y sincrónicamente debe partir en el campo educativo, como se sostiene más adelante. Es decir, de una disposición de apertura al otro a través de la formación de la conciencia y la superación del egocentrismo individual y colectivo presente en maestros y alumnos, como requisito de una auténtica educación intercultural. En este sentido supone, no solo una propuesta para la convivencia, sino una relación intersubjetiva e intercultural fundamental (Lara, 2015).

Ahora bien, en cuanto a la realidad educativa ecuatoriana se plantea la siguiente pregunta: ¿Qué elementos fundamentales son los que configuran el derecho a la educación en Ecuador? Con la intención de responder a la anterior cuestión se parte de cómo queda articulado el derecho a la educación del buen vivir en las principales normas educativas ecuatorianas de una manera sucinta: 
- Constitución de la República del Ecuador (CRE, 2008).

- Ley Orgánica de Educación Intercultural (LOEI, 2011).

- Reglamento General a la Ley Orgánica de Educación Intercultural (RLOEI, 2012).

- Ley Orgánica de Educación Superior (LOES, 2010).

- Plan Nacional del Buen Vivir 2013-2017 (SENPLADES, 2013).

De este modo se escogerán los preceptos normativos considerados esenciales para poder entender qué se quiere plantear en Ecuador como educación para el buen vivir como punto de partida y así poder abrir un marco jurídico que abarque el espacio de diálogo y reflexión pretendidos en esta investigación.

Entre los "derechos del buen vivir" consagrados en la CRE (2008) (alimentación, ambiente sano, agua, comunicación, vivienda, etc.) se ubica el derecho a la educación (arts., 26, 27, 28 y 29), configurado como un derecho centrado, entre otros elementos, en el ser humano como realidad compleja que apuesta por un diálogo intercultural como eje para el aprendizaje y la evolución de una conciencia ecológica del buen vivir.

Ecuador, al igual que otros países de América Latina, tiene como cualidad enriquecedora la presencia de un pluralismo cultural integrado en el discurso del buen vivir. Por lo tanto, para saber qué supone esta realidad educativa o cómo comprenderla habría que preguntarse acerca de cómo hacer educación para la convivencia, reconociendo las distintas culturas, filosofías y visiones del mundo.

Además, la interculturalidad educativa que se pretende desde el buen vivir se traduce en una competencia fundamental denominada "conciencia intercultural", que se enmarca dentro de las competencias definidas por la UNESCO (2008): comprensión, pensamiento crítico, creatividad, conciencia intercultural y ciudadanía.

En este sentido se defiende la interculturalidad como cualidad necesaria a obtener por los ecuatorianos y sus distintas culturas que las conforman para poder vivir en armonía, plenitud y en permanente respeto. Esto es lo que los pueblos indígenas califican, entre otros términos, como sumak Kawsay (quechua) o Shiirwaras (ashuar).

Así se refleja en el art. 27 y 28 de la CRE (2008) al señalar respectivamente que la "educación será intercultural", y que "es derecho de toda persona y comunidad interactuar entre culturas y participar en una sociedad que aprende". Ahora bien, ¿cómo queda definida la interculturalidad como competencia a adquirir?

La LOEI (2010) en su artículo 79 d) entiende la interculturalidad como "la coexistencia e interacción equitativa, que fomenta la unidad en la diversidad, 
la valoración mutua entre las personas, nacionalidades y pueblos en el contexto nacional e internacional". Acerca de un concepto de interculturalidad, FornetBetancourt (2002) propone:

se trata de una cualidad que puede obtener cualquier persona y cualquier cultura a partir de una praxis de vida concreta en la que se cultiva precisamente la relación con el otro de una manera envolvente, es decir, no limitada a la posible comunicación racional a través de conceptos sino asentada más bien en el dejarse afectar, tocar, impresionar por el otro en el trato diario de nuestra vida cotidiana. (p. 126)

Por lo tanto, en cuanto a una posible aproximación sobre qué puede suponer o cómo debe hacerse la realidad educativa ecuatoriana en relación con relación a lo expuesto, se entiende como una educación que tiene como finalidad la de preparar a personas para poder vivir en una sociedad en la que el otro o el saber vivir con el otro implica la actitud de dejarse afectar por "nuestra" cultura y "su" cultura, las "distintas", y sus "diferencias" en términos de igualdad, a través de un necesario fomento del diálogo intercultural; la interculturalidad, por lo tanto, se concibe como una cualidad necesaria precisa para que el ser humano (entendido como realidad compleja) esté dispuesto a aprender y a enseñar en el proceso de diálogo intercultural.

\section{El diálogo intercultural como medio de educación}

La configuración del derecho a la educación en el buen vivir tiene como eje fundamental la apuesta por la consecución de la interculturalidad, como queda reflejado con la promulgación de la LOEI (2011) y su Reglamento de desarrollo RLOEI (2012). Esta última norma señala en este sentido que se propone un enfoque educativo inclusivo mediante la valoración de la diversidad cultural y el respeto a las distintas culturas que existen en el Ecuador, favoreciendo la comunicación entre los miembros de las diferentes culturas (art. 243). Del mismo modo concibe su necesaria transversalización en todos los ámbitos de la práctica educativa (art. 244). Por ejemplo, se establece en la política 8 del objetivo 4 del Plan Nacional del Buen Vivir 2013-2017, que señala la importancia de "impulsar el diálogo intercultural como eje articulador del modelo pedagógico y del uso del espacio educativo" (SENPLADES, 2013), creando una comunidad de aprendizaje integrada por alumnos y maestros (LOEI, art. $2 \mathrm{n}$ ).

Constitucionalmente queda preceptuado en el párrafo $2^{\circ}$ del art. 28 de la CRE (2008) al señalar la importancia que tiene el diálogo intercultural como eje para el aprendizaje al señalar: "Es derecho de toda persona y comunidad interactuar entre culturas y participar en una sociedad que 
aprende. El Estado promoverá el diálogo intercultural en sus múltiples dimensiones". Supone en consecuencia, consagrar como parte del derecho a la educación, el diálogo intercultural como medio de aprendizaje.

Por lo tanto, la interculturalidad se percibe como un elemento central del aprendizaje, que tiene como eje fundamental la persona y su realidad cultural, esto es, se aprende en la relación con el otro. Ahora bien, si es el reconocimiento de la diversidad y complejidad de la persona el punto de partida para ese aprendizaje, se colige en considerar la valía de cada persona y cultura.

\section{La evolución a una conciencia ecológica del buen vivir desde la complejidad}

El enfoque de la interculturalidad en el ámbito educativo supone un ejercicio dialéctico, no solo en cuanto a las distintas culturas indígenas y no indígenas existentes en Ecuador, sino también con la propia naturaleza a la que pertenece el ser humano, como se refleja en el preámbulo: "somos parte" (CRE, 2008), y que es sujeto de derechos (CRE, 2008, art.71, 72, 73 y 74). La particularidad de reconocer a la naturaleza como sujeto de derechos supone una novedad digna de recogerse en cualquiera investigación de derecho comparado con relación a otras regulaciones jurídicas actuales, no solo en cuanto a la región latinoamericana sino también mundial tanto en cuanto eleva su condición jurídica de objeto a sujeto de derechos.

Esto viene a suponer una necesaria reflexión acerca de la relación hombre-sociedad con la naturaleza, pues la Pacha Mama como sujeto de derechos es, de esta manera, incluida por el legislador ecuatoriano como un derecho fundamental más que requiere garantizar y proteger, y por esta razón, un aspecto que debe estar presente en la cultura política educativa del Ecuador. Se ubica en igual jerarquía a la persona, sociedad y naturaleza.

Asimismo, un elemento principal de este derecho es la destinada a fomentar el pensamiento crítico con vocación universal que, en palabras del legislador, supone la de formar a sujetos críticos y activos para que se inserten en el mundo con vocación transformadora (LOEI, 2011, art. 3 d; LOES, 2010, art.8 b).

El legislador viene a declarar, por consiguiente, un compromiso más allá de los problemas propios del Ecuador, al añadir la preocupación por los problemas globales como por ejemplo es la sustentabilidad ambiental, lo que significa hablar de una educación para la universalidad. Esto queda reflejado al señalar como una finalidad de la educación la de fomentar y desarrollar una conciencia ecológica, es decir, una conciencia "ciudadana" y "planetaria" para la conservación, defensa y mejoramiento del ambiente; para la consecución de una vida sana y para el uso racional, sostenible y sustentable de los recursos 
naturales (LOEI, 2011, 3 f; LOES, 2010, 3f). Especialmente, el objetivo 7 del Plan Nacional del Buen Vivir 2013- 2017 señala el de "garantizar los derechos de la naturaleza y promover la sostenibilidad ambiental territorial y global" (SENPLADES, 2013).

Así, se puede advertir en su articulado la necesaria contemplación del pensamiento complejo como otro punto esencial en esta labor de descifrar qué supone o puede suponer una educación para el buen vivir. En este sentido, se señala en distintas normativas, a las que anteriormente se ha hecho referencia, el compromiso con los problemas que van más allá de Ecuador, como es la sustentabilidad, comprendida como nuevo problema de la colectividad, pero reconociendo como camino a seguirla formación de una conciencia ecológica que integre a la naturaleza.

En efecto, García (2014) señala con relación a "Los siete saberes necesarios para la educación del futuro" de Morin, que:

Un modelo educativo basado en los criterios del pensamiento complejo debe, además de estar orientado hacia un fin humanista, propiciar en el alumno un alto grado de alfabetización científico-tecnológica, ya que los problemas actuales reflejan a nivel global, la demanda de resolver un gran caudal de problemas científicos y tecnológicos, no solo en escenarios especializados, sino a nivel de cualquier persona en su vida cotidiana. Esto ha derivado en la "revolución informativa", que ha originado una nueva manera de relaciones interpersonales y una nueva forma de pensar. (p.27)

A modo de síntesis:

-Se reconoce la importancia de la construcción de la conciencia ecológica como tarea de la educación y como fin en sí mismo.

-Se parte de la necesaria formación de una conciencia social y humanista que integre los problemas del mundo actual al señalar la necesidad de fomentar y desarrollar una conciencia "ciudadana" y "planetaria", esto es, una educación para la universalidad (Herrán y Muñoz, 2002) partiendo de la propia conciencia.

-Asimismo, una educación para el buen vivir supone contemplar en su configuración la integración de la relación con la Pacha Mama; pues al ser sujeto de derechos y situada en la misma línea de protección y garantía que el ser humano, parece que debe traducirse (relación con la naturaleza) en un necesario reconocimiento como elemento fundamental para el aprendizaje. 


\section{El reconocimiento del ser humano como realidad compleja}

La educación debe centrarse en la persona en todas sus dimensiones, entendida de una manera holística como así señala el art. 27 de la CRE (2008): "La educación se centrará en el ser humano y garantizará su desarrollo holístico". Asimismo reconoce la educación como un proceso que debe estar presente a lo largo de su vida: "La educación es un derecho de las personas a lo largo de su vida" (CRE, 2008, art. 26).

A la luz de los preceptos anteriores, existe un reconocimiento constitucional de las distintas facetas del ser humano, huyendo de esta manera de cualquier reduccionismo o parcialidad. De este modo, es la ley la que exige la búsqueda de la integración de la complejidad como medio de abordar el desarrollo holístico del ser humano, esto es, su realidad. Con relación a esta preocupación, Castellano (2007) recuerda que el ordenamiento jurídico no puede estar simplemente subordinado a la persona sino a su "perfección intelectual, moral y religiosa según la ley natural” (p. 82). Por lo tanto, supone una recomendación revestida de legalidad la que aconseja la integración del paradigma de la complejidad en las aulas entendidas éstas en sentido amplio.

El reconocimiento de la complejidad en la realidad personal que parece darse en la legislación educativa, parte del recogimiento y apreciación de la diversidad de cada persona. Por ejemplo, la intimidad propia de cada individuo -que según define la Real Academia Española (2015) hace referencia a espiritualidad íntima de cada persona- queda atendida por el legislador ecuatoriano en el artículo 11 de la LOEI (2011), en sus letras n) y h), al establecer, respectivamente, que es una obligación de los docentes el "cuidar la privacidad e intimidad propias y respetar la de sus estudiantes y de los demás actores de la comunidad educativa", "atender y evaluar a las y los estudiantes de acuerdo con su diversidad cultural y lingüística y las diferencias individuales".

Por otro lado, si se regula un derecho a la educación a lo largo de la vida hasta la muerte (art. $26 \mathrm{CRE}, 2008$ ), supone concebir el paso del tiempo como una oportunidad para la esperanza y el mejoramiento permanente. Así, si se persigue una educación intercultural en la que se reconoce la diversidad de cada persona y su propio valor, la educación deberá orientarse hacia el desarrollo de una cultura del buen vivir en la que la edad adulta pueda ser entendida como una etapa privilegiada de existencia (sabiduría, paz y experiencia) (De Beauvoir, 2011). Esto es, valorando las distintas realidades culturales propias de cada persona y edad, con sus peculiaridades y también teniendo presente, como cualquiera otra realidad personal y social, su particular idiosincrasia.

Volviendo a la literalidad del precepto ligado al carácter intercultural de la educación, el derecho a la educación no puede reducirse, por lo tanto, al derecho de todos a ser educados, sino también al de educar. Esto es, a concebir 
al ser humano como sujeto de aprendizaje formativo y como maestro. En otras palabras, puede colegirse el derecho a aprender y educarme mediante mi experiencia con el otro, y del otro a través de su experiencia conmigo.

En este sentido, si se quiere contemplar de manera holística la realidad personal, también se debe evitar una educación que prescinda de todo lo que el ser humano como ser experiencial "vive", evitando la parcialidad o reduccionismo consentido, así como la compleción como explicación total. Por el contrario, lo que se defiende es la complejidad (García, 2014). De ahí que se deban incluir nuevas pedagogías que atiendan, por ejemplo, el sufrimiento ante la pérdida de un ser querido, el despido de un trabajo, una crisis sentimental o la preparación ante la muerte como un hecho propio de la vida y necesario para amar la vida, como explica Unamuno (2004): "qué fecundas paradojas la de la vida de la muerte y la muerte de la vida" (p. 49), "solo se suicida el que odia a la muerte; los melancólicos enamorados de ella viven para gozar en esperarla, y así, cuanto más tiempo la esperan más tiempo gozan” (p. 94).

\section{Aproximación a una conciencia del buen vivir}

\section{Hacia una definición de conciencia del buen vivir}

El legislador ecuatoriano se detiene en sus diversas normas educativas indicando la necesidad de crear una conciencia, calificada como propia del buen vivir, al reconocer el valor de la filosofía indígena. Sin embargo, está abierta a las aportaciones de la sabiduría de las demás sociedades que componen la humanidad y de los pueblos que han "forjado" el Ecuador de hoy, como hemos visto que incluye y demanda el preámbulo de su Constitución (CRE, 2008).

De este modo, a través de los siguientes artículos de la LOEI (2011) y en la declaración de intenciones que se establece en el Plan nacional del Buen Vivir 2013- 2017 (SENPLADES, 2013), el legislador enumera y define las exigencias a las que debe responder esa conciencia:

1) La LOEI (2011) en su art.3 d) y f) la califica como una conciencia "crítica" con vocación transformadora en el mundo, "ciudadana" y "planetaria" respectivamente.

2) Por otro lado, el SENPLADES (2013) señala que la finalidad de la Universidad Tecnológica de Yachay es la de crear talento humano con conciencia "ética" y "solidaria".

Esta conciencia es también denominada por algunos autores "conciencia de especie", pues propone al ser humano una percepción del espacio y del 
tiempo distinta al individualista y racional propia de la visión occidentalista. Aquélla pone énfasis en una relación de dependencia mutua entre el ser humano y la naturaleza, es decir, defiende una racionalidad sistémica (Vanhulst y Beling, 2013) que huye de los localismos o nacionalismos como categorías de pertenencia excluyentes, y que apuesta, por consiguiente, por una categoría de pertenencia universal y comprometida con el futuro del ser humano.

Esta cosmovisión parece advertirla Unamuno (2005), al enfatizar en la relación ética del ser humano con el entorno y la incorporación de los afectos a esa nueva percepción del contexto, pues "para amarlo todo, para compadecerlo todo, humano y extrahumano, viviente y no viviente, es menester que sientas todo dentro de ti mismo, que lo personalices todo" (p.281). Durkheim (citado por Bolado, 2014) introduce la noción de una conciencia colectiva o común, de carácter moral y jurídica, constituida por patrones ejecutivos colectivos, vigentes, que componen una especie de sistema con vida propia, y que operan como una fuerza integradora dentro de la sociedad. Estas vigencias ejecutivas colectivas no se basan por completo en la razón, sino que pertenecen al ámbito de los sentimientos, de las creencias y de los hábitos.

Asimismo, Nussbaum (2010) defiende que una educación preocupada por el futuro de la democracia actual debe incorporar en sus programas de enseñanza materias humanísticas y experiencias formativas artísticas que estimulen "la capacidad de desarrollar un pensamiento crítico; la capacidad de trascender las lealtades nacionales y de afrontar los problemas internacionales" como "ciudadanos del mundo"; y, por último, "la capacidad de imaginar con compasión las dificultades del prójimo” (2010, p. 26).

\section{¿Qué hay que buscar para crear esa conciencia?}

¿Cómo se puede crear esa conciencia del buen vivir? ¿Qué parece decir la ley educativa ecuatoriana? Una primera aproximación podría proceder de una necesaria evolución de la conciencia, partiendo de una precisa justificación de una educación de calidad.

Ahora bien, ¿qué supone para el legislador ecuatoriano una legislación de calidad? La respuesta a la pregunta se puede hallar en la LOES (2010), en su artículo 93, que dice: "el principio de calidad consiste en la búsqueda constante y sistemática de la excelencia, la pertinencia, producción óptima, transmisión del conocimiento y desarrollo del pensamiento mediante la autocrítica, la crítica externa y el mejoramiento permanente".

Para la cuestión tratada se aconseja el análisis detenido de este artículo tanto en cuanto el legislador define qué entiende por calidad y cómo conseguirla, es decir, el método. Así, define en su primera parte lo que se entiende por calidad en la educación: "búsqueda constante y sistemática de la excelencia, la 
pertinencia, producción óptima, transmisión del conocimiento y desarrollo del pensamiento", y en segundo lugar, el método para su consecución: "mediante la autocrítica, la crítica externa y el mejoramiento permanente".

Por lo tanto, se parte de la exigencia de impulsar la autocrítica como método para alcanzar la calidad educativa. Esto supone un llamamiento socrático a la humildad (conócete a ti mismo) como medio para superar el egocentrismo, entendido como aquella exaltación de uno mismo reflejada tanto en la propia realidad de la persona como en la colectividad. Es decir, para crear esa conciencia hay que partir de la exigencia de buscarse a sí mismo y eso pasa por discriminar nuestro egocentrismo de nuestra verdadera identidad.

El egocentrismo, en este sentido, viene a suponer una barrera para el autoconocimiento y la educación intercultural, por cuanto desplaza a la conciencia entendida como conocimiento reflexivo de las cosas. Así pues, esta conciencia debe estar abierta al otro y estar preparada para aprender o enseñar mediante el diálogo como método de una educación intercultural.

La autocrítica, de este modo, se constituye como medio de reconocimiento del propio egocentrismo personal y colectivo (por ejemplo, el etnocentrismo), constituyéndose como el punto de partida para una educación a través del otro, esto es, en relación con los demás para la evolución de la conciencia conjunta, y para el desempeoramiento y mejoramiento permanentes.

Así, la educación para el buen vivir y, en palabras de Herrán (2011) cualquier educación, se ha de traducir en la evolución del ser humano, concebida como la "creciente complejidad de conciencia acompañada de la reducción de egocentrismo, individual y colectivo. Todo estrechamiento, toda miopía avalada o pretendida no coincide con ningún fin de la educación, ni debiera someter el conocimiento de ningún educador" (p. 247).

De este modo, para la construcción de una conciencia del buen vivir el legislador somete al educador a la tarea de conocerse mejor, mediante la reflexión personal como camino hacia la humildad necesaria, que pueda coadyuvar a la creación de la conciencia propia que desplace al egocentrismo como obstáculo principal en la relación intercultural intersubjetiva, esencial para el aprendizaje que configura la normativa educativa ecuatoriana.

\section{Fundamentos de pedagogías para el sumak Kawsay}

Se recomienda abordar la cuestión planteada desde un punto de vista teleológico. Es decir, fomentando la dialéctica sobre las posibles finalidades de la educación en Ecuador, para aprender a saber vivir en equilibrio con toda forma de existencia en permanente respeto. De esta manera, si se pretende describir qué puede significar el derecho a la educación en Ecuador, se 
debe igualmente trasladar su significado a las políticas educativas, planes curriculares y a las propias aulas. En otras palabras, mediante la aplicación de metodologías educativas que sean didácticas, en la medida en que se tenga presente su finalidad durante su implementación.

La interculturalidad como competencia se podrá construir en la medida que exista una apuesta por el desarrollo e implementación de herramientas de comunicación que sirvan para facilitar este diálogo. Para ello, resulta necesario y pertinente la apertura de un debate acerca de posibles pedagogías que vengan a proponer vías para la convivencia, basada en la igualdad y en la diversidad de culturas. O bien, que las existentes apuesten por integrar una educación intercultural que permitan afectar o ser afectado por el otro. Es decir, de modo que permitan comprender el alejamiento cultural traducido en distintas maneras de percibir la realidad, procesos cognitivos, patrones de comportamientos, formas lingüísticas, estructuras sociales, recursos motivacionales, patrones de comportamiento y la influencia de las distintas maneras de canalizar el mensaje (Hesselgrave citado por De Vallescar, 2002).

Por lo tanto, en la discusión de una educación para la práctica de la interculturalidad parece necesario reconocer y comprender las propias necesidades educativas del país en su conjunto y en su especificidad, respetando los contextos, las diferencias y las particularidades, reconociendo los caminos recorridos, las luchas históricas por la educación, por la autonomía y la pertinencia educativa (Villagómez y Cunha de Campos, 2014), mediante la creación de una conciencia en la persona que pueda apreciar la riqueza de la complejidad, y advertir los egocentrismos reductores.

En este sentido y en cuanto a las posibles pedagogías que puedan encuadrarse en este discurso, se requieren alternativas que, por lo expuesto anteriormente:

-Incluyan categorías como la esperanza, la autocrítica, el egocentrismo, la percepción universal del espacio y del tiempo, etc. de modo que sean concebidas para la mejora de la persona y del colectivo.

-Valoren la complejidad de la realidad personal y cultural como riqueza para la mutua educación y la convivencia.

-Se comprometan expresamente con los problemas y soluciones globales que, como ciudadanos del mundo, puedan experimentarse.

Desde estas perspectivas tendrá más sentido la reflexión permanente de qué supone el buen vivir, mediante una necesaria preocupación por realizar una adecuada didáctica de la cultura política educativa.

Los distintos y numeroso retos existentes en el panorama actual de la educación ponen de actualidad cualquier espacio de discusión acerca del 
significado de este derecho fundamental. Como así se intenta realizar en este caso con Ecuador, por cuanto parte de una filosofía particular distinta a la occidental. Sin embargo, creemos que es conveniente advertir algunas de las dificultades principales a las que a nuestro juicio tiene que hacer frente la puesta en valor del derecho a la educación en Ecuador:

-Escasa cultura política educativa: "conceptos de sumak Kawsay, Pacha Mama, cosmovisión y consejo de ancianos aún siguen segregados en las propuestas curriculares y pedagógicas" (Illicachi, 2015, p. 225). En el panorama educativo actual se percibe una preocupación ante las alertas de conversión de la educación en un mero objeto al servicio del progreso económico basado en el individualismo, en detrimento del pensamiento crítico y del desarrollo íntegro de la persona (Nussbaum, 2010). De esta manera, desde distintos sectores académicos se reivindica e invita a una reflexión, de la que no puede escapar la realidad ecuatoriana; que se traduce en un compromiso con el hombre, la sociedad y la sustentabilidad ambiental como problema principal de la colectividad, y que cuestiona el rumbo actual del mundo globalizado. En este sentido, la propuesta educativa que supone el buen vivir debe estar acompañada por un compromiso con su desarrollo que, sin embargo, se colige complicado por cuanto aún no está resuelto el alcance del significado acerca de este concepto para las distintas disciplinas y sectores (Fernández y otros, 2014), y que también se traslada a la educación.

-Egocentrismo cultural: "cada cual llama barbarie a lo que es ajeno a sus costumbres" (Montaigne, 2010). En la necesaria comprensión del otro, resulta necesario advertir de los posibles peligros que pueden surgir en ese encuentro para una educación intercultural, como el etnocentrismo, entendido como aquella carencia de comprensión resultante de la valoración del otro desde la propia identidad cultural. Por ejemplo, el egocentrismo de la cultura dominante mestiza ante las diferencias culturales existentes, proclive a defender un discurso de la cohesión social (Vargas, 2014; Villagómez y Cunha de Campos, 2014). Y el relativismo, al valorarse por igual todas las culturas en el sentido de que se limita su comprensión a sus propios contextos culturales y solo a ellos; de este modo, la preocupación de afectar o ser afectado por el otro puede no tener ningún valor, y la interculturalidad como competencia a adquirir quedaría desvirtuada, al no percibirse que se pudiese alcanzar el aprendizaje mediante la relación intercultural que enfatiza el ordenamiento jurídico educativo ecuatoriano. 
-Calidad de la universidad y vinculación JCR: Ecuador se encuentra en un proceso de reivindicación de la calidad en la educación superior, en los ámbitos docentes, de vinculación con la sociedad y en investigación. En este último ámbito se pueden evidenciar características parecidas a los vividos en otros países Europeos. Así pues, se exigen estándares de calidad en la investigación con rasgos similares a sistemas de educación superior occidentales, como por ejemplo es la introducción y globalización de la llamada "cultura JCR", actualmente cuestionada (Herrán y Villena, 2012). Sin entrar en el posible debate acerca de su validez como criterio de medición de la calidad de la educación superior, sí podría criticarse su inclusión obligatoria como indicador coherente con el marco político jurídico de la educación que se plantea en Ecuador, cosa que en nuestra opinión necesitaría de un debate detenido. En efecto, es la propia LOES (2010) la que por medio de su artículo 93 (antes citado) relaciona el principio de calidad con el fomento del pensamiento crítico para la mejora permanente (autocrítica y crítica externa). Por lo tanto, puede resultar conveniente tener presente dicha discusión en relación con la dirección de la educación superior ecuatoriana. Es decir, hasta qué punto la concepción de calidad vigente en otros contextos culturales puede entenderse transferible al Ecuador. O, por el contrario, si podría ser entendida dicha calidad como resultado de un diálogo exitoso.

-Complejo cultural: aunque existe un reconocimiento jurídico y político de la interculturalidad, aún parece apreciarse un sentimiento de complejo colonial al considerarse (de manera generalizada en muchas ocasiones), que la lógica europea o americana es superior a la propia. Esto provoca una autodepreciación de la riqueza existente en Ecuador en cuanto a la pluralidad y diversidad cultural (Illicachi, 2015), reflejada en la praxis educativa.

\section{Conclusiones}

La educación como derecho fundamental y esencial para el desarrollo de la convivencia que supone el buen vivir en Ecuador necesita de una debate fundamental acerca de su significación y de los elementos que la definen. Estos elementos están presentes en cualquier política educativa y en la preparación y desarrollo de cualquiera clase del docente ecuatoriano. Estéril sería cualquier discusión acerca del derecho a la educación (exigencia o evaluación) si se desconoce su significado y finalidad. De este modo, se estima esencial su permanente discusión. 
Si ambicioso es definir lo que es el derecho a la educación, más se complica al considerarlo integrado en una cosmovisión que, tanto en el plano de la políticas como en los desarrollos concretos aún se encuentra en ciernes conceptualmente, aunque debe animar a la comunidad para plasmar la ambición de esta propuesta educativa.

La legislación educativa ecuatoriana demanda la inclusión de la interculturalidad como eje para la educación, la defensa de la concepción de la realidad personal y colectiva desde la riqueza de la complejidad y la universalidad como compromisos con el futuro de los ecuatorianos y del mundo.

Una pedagogía que no incluyese estos elementos como principios fundamentales sería de difícil encaje en la configuración de este derecho.

Se demanda el ejercicio e implantación de la autocrítica y la crítica externa como medio educativo para el reconocimiento y superación del egocentrismo personal y colectivo, presente en cualquier sistema humano -por ejemplo, el etnocentrismo cultural del mestizaje-.

En este sentido se debe tener presente la importancia de crear una conciencia intercultural en la que la educación sea concebida en clave de la relación con el otro, incluyendo necesariamente en la ecuación a la naturaleza. 


\section{Referencias bibliográficas:}

Bolado, G. (2014). Influencia y contextos europeos de la filosofía contemporánea en lengua española: Génesis y sentido en la creencia en la obra de Ortega y Gasset. En H. Arévalo, G. Bolado y F. La Rubia (Eds.), Entre Europa y América. Estudios de Filosofía Contemporánea en lengua española, (pp. 87-135). Loja: Universidad Técnica Particular de Loja.

Castellano, D. (2007). L'ordine politico-giuridico "modulare" del personalismo contemporáneo. Nápoles: Edizioni Scientifiche Italiane.

Constitución de la República del Ecuador (2008). Ciudad Alfaro: Asamblea Constituyente.

De Beauvoir, S. (2011). La Vejez. España: Debolsillo.

DeVallescar,D. (2002). La cultura: consideraciones para el Encuentro Intercultural. En G. González, (Coord.), El discurso intercultural: prolegómenos a una filosofia intercultural (pp. 141-162). Madrid: Biblioteca Nueva.

Fernández, B. S. Pardo, L. y Salamanca, K. (2014). El buen vivir en Ecuador: ¿marketing político o proyecto en disputa? Un diálogo con Alberto Acosta. Iconos. Revista de Ciencias Sociales (48), 101-117.

Forner-Betancourt, R. (2002). Filosofía e interculturalidad en América Latina: intento de introducción no filosófica. En G. González (Coord.), El discurso intercultural: prolegómenos a una filosofía intercultural (pp. 123-140). Madrid: Biblioteca Nueva.

García, E. (2014). Edgar Morin. La nueva realidad de la enseñanza. México: Trillas.

Herrán, A. (2011). Reflexiones para una reforma profunda de la educación, desde un enfoque basado en la complejidad, la universalidad y la conciencia. Educación XXI, 14 (1), 245-264. doi: 10.5944/educxx1.14.1.271

Herrán, A. y Muñoz, J. (2002). Educación para la universalidad. Más allá de la globalización. Madrid: Dílex.

Herrán, A. y Villena, J.L. (2012). La 'cultura del impacto JCR': El caso del área de Didáctica y Organización Escolar. En A. de la Herrán y J. Paredes (Coords.), Promover el cambio pedagógico en la universidad (pp. 287304). Madrid: Pirámide.

Hurtado, O. (2007). Las costumbres de los ecuatorianos. Barcelona: Planeta.

Illicachi, J. (2015). La educación intercultural bilingüe como proyecto epistémico de los movimientos indígenas en el Ecuador. Sophia, Colección de Filosofía de la Educación, 18 (1), 211-229. doi:10.17163/ soph.n18.2015.11

Lara, F. (2015). Personalismo en la legislación educativa ecuatoriana: una aproximación desde el pensamiento de Gabriel Marcel.Academia, (Número 
Especial: III Congreso Internacional de la Asociación Iberoamericana de Personalismo, Loja-Ecuador), 230-238. Recuperado de http://www.saber. ula.ve/bitstream/123456789/41273/3/articulo24.pdf

Ley Orgánica de Educación Intercultural (2011). Quito: Asamblea Constituyente. Ley Orgánica de Educación Superior (2010). Quito: Asamblea Constituyente. Montaigne, M. (2010). Ensayos escogidos. Medellín: Universidad de Antioquía. Navarro, M. (2010). El final de una tensión esencial: analíticos y continentales. Herméutica filosófica y teorías de la argumentación. Arbor, 186 (742), 321-338 doi:10.3989/arbor.2010.742n1111

Nussbaum, M.C. (2010). Sin fines de lucro. Por qué la democracia necesita de las humanidades. Madrid: Katz.

Real Academia Española (2015). Diccionario de la lengua española. Recuperado de http://lema.rae.es/drae/?val=intimidad

Reglamento General a la Ley Orgánica de Educación Intercultural (2012). Sozoranga: Presidencia de la República.

Rodríguez, C. (2015). La educación intercultural bilingüe en el Ecuador del Buen Vivir. De la normativización legislativa a la praxis educativa. En J.M, Gómez, S. Méndez, N, García \& M.J, Cartes (eds), Derechos humanos emergentes y periodismo, (pp.565-692). España: Universidad de Sevilla.

SENPLADES (2013). Buen Vivir: Plan Nacional 2013-2017. Ecuador: SENPLADES

Unamuno, M. (2004). Amor y Pedagogía. Madrid: Alianza Editorial.

Unamuno, M. (2005). Del sentimiento trágico de la vida en los hombres y en los pueblos. Madrid: Tecnos.

UNESCO (2008). Teacher Training Curricula for Media and information Literacy. Report of the International Expert Group Meeting. Paris: UNESCO.

Vanhulst, J. y Beling, A. E. (2014). El Buen vivir: una utopía latinoamericana en el campo discursivo global de la sustentabilidad. Polis, 12 (36), 497522.

Vargas, P.A. (2014). Educación Superior Intercultural en disputa. Trayectorias de la Universidad Intercultural Amawtay Wasi. Polis, 13, 269-300.

Villagómez, M. S. y Cunha de Campos, R. (2014). Buen vivir y educación para la práctica de la interculturalidad en el Ecuador. Otras prácticas pedagógicas son necesarias. Revista Alteridad, 9 (1), 35-42. doi: 10.17163/ alt.v9n1.2014.03

Zubiri, X . (2005). ¿Qué es investigar? The Xavier Zubiri Review (7), 5-7. Recuperado de biblio3.url.edu.gt/Libros/investigar.pdf 